Europe's Journal of Psychology, 7(3), pp. 458-486

www.ejop.org

'I think a fair girl would have better marriage prospects than a dark one': British Indian adults' perceptions of physical appearance ideals

\title{
Savita Bakhshi
}

London Metropolitan University

\section{Anna Baker}

London Metropolitan University

\begin{abstract}
The aim of the present study was to investigate British Indian men and women's perceptions of Indian physical appearance ideals and related attributes. Eight semistructured interviews with men and women were conducted, and the data were analysed using Interpretative Phenomenological Analysis. Four themes emerged from the data: 1) Cultural similarities and differences in physical appearance, 2) Gender differences in pressure experienced, 3) Improving physical appearance for marriage, and 4) Factors influencing appearance pressures. The findings indicated that participants perceived few cultural similarities in the Indian and Western standards for physical appearance. Internalisation of Indian body ideals (including fair skin and slimness) were linked to finding a suitable partner for marriage for women, and this pressure was largely perceived to be influenced by maternal encouragement and the media. The results indicate that gender is influential in determining the physical, psychological and social implications of attempting to conform to the cultural physical appearance ideals and related attributes.
\end{abstract}

Keywords: Appearance ideals; British Indian; marriage; qualitative; skin colour

Body image has been described as a combination of a person's perceptions and feelings about his/her body and their general physical appearance (Cash \& Henry, 1995). It can be thought of as an individual's body size estimation and an evaluation of their body attractiveness as compared to the appearance ideals accepted in a culture. Research acknowledges that culture plays a significant role in forming 
appearance ideals, and that these vary for men and women across societies and cultures (Fallon, 1990; Grogan, 2006). These ideals are generally perceived as a criterion for evaluating personal standards for attractiveness, and may be reinforced through processes such as social comparison and internalisation (Strahan, Wilson, Cressman \& Buote, 2006; Gillen \& Lefkowitz, 2009). Such messages may be so pervasive that they take precedence over emotional, social, cultural, spiritual and physical health and well-being (Paquette \& Raine, 2004).

\section{Cultural ideals and differences}

The ideal male and female body shapes and sizes have changed significantly over the last century (Wiseman, Gray, Mosimann \& Ahrens, 1992). Western cultures present the ideal female body as thin and slender, whereas the ideal male body is portrayed as having well-developed muscles on the chest, arms and shoulders, with a slim waist and hips (Grogan, 1999; Ogden, 2010). In contrast, many non-Western cultures have been shown to devalue such ideals, as larger body sizes and shapes are considered more attractive (Nasser, 1988, 1997). For example, although body weight, shape and size is important to men and women of non-Western backgrounds, the need to conform to the Western ideals of thinness for women and muscularity for men may not be as strong as in the West (Wardle, Bindra, Fairclough \& Westcombe, 1993; Reddy \& Crowther, 2007). Detailed explanations of how cultures construct and change body ideals for men and women can be found in Nasser (1997) and Grogan (1999).

Warren, Gleaves, Cepeda-Benito, del Carmen Fernandez and Rodriguez-Ruiz (2005) proposed that non-Western cultures provide people with larger, more realistic and attainable physical ideals, protecting people from developing a negative body image. In India, for example, the prevalence of eating disturbances are rarely reported, perhaps due to the traditional Indian culture which does not encourage thinness as a symbol of feminine beauty (Dasgupta, 1998; Malhotra \& Rogers, 2000; Furnham \& Adam-Saib, 2001). Furthermore, non-Western cultures place less value on physical appearance as a defining feature of a woman's worth, her role in society, and as an indicator of success (Bush, Williams, Lean \& Anderson, 2001). This is in contrast to the West where women's appearance is viewed as important feature for competitiveness, achievement and professional success (Stice, 1994; McKinley, 1999; Cheney, 2010). Thus, non-Western men and women may not internalise such information because they have an affiliation with a culture that does not support such values and ideals (Wood-Barcalow, Tylka \& Augustus-Horvath, 2010). 
However, other research has shown that some non-Western cultures may not be protecting people from developing body weight and shape concerns. Grabe and Hyde (2006) investigated body dissatisfaction levels among women of different ethnic groups and found that various non-White groups are showing similar rates of body dissatisfaction compared to Whites. The study found that Asians are also likely to conform to the thin Western ideal due to processes such as acculturation and integration (i.e. 'the extent to which individuals have maintained their culture of origin or adapted to the larger society', Farver, Bhadha \& Narang, 2002, p.12) into the dominant Western culture, which may be in conflict with the ideals of their native country (Dasgupta, 1998; Ball \& Kenardy, 2002; Cheney, 2010). Other research (predominately examining American samples) has found that Asian women report similar levels of eating disturbances, slightly more weight and diet concerns, and greater dietary restraint compared to Whites (Wildes, Emery \& Lehman, 2007; Cummins \& Lehman, 2007). Thus, Asian groups are also susceptible to body image concerns just like White groups (Kennedy, Templeton, Gandhi \& Gorzalka, 2004). Nevertheless, non-Western groups have also shown an acceptance for their bodies for the way they are (Bush et al., 2001; Wood-Barcalow et al., 2010), suggesting that although ethnicity is an important influence on body image, differences across and within groups are likely to occur.

\section{A preference for fair skin?}

Body image should not be perceived as a whole entity, as it includes different facets such as hair, skin, weight, shape, structure, etc. In non-Western cultures, other appearance-related features may be considered as equally significant in defining a person's appearance and ideals, than simply their body weight, shape and size (Swami et al., 2008b; Callister, Galtry \& Didham, 2011). For example, a preference for fair skin has been found in various studies, as it has been found to be commonly associated with beauty (Sahay \& Piran, 1997; Badruddoja, 2005; Jha \& Adelman, 2009), physical attractiveness (Frisby, 2006), as well as health and fertility (Swami, Furnham \& Joshi, 2008a). Historically, the Aryan invasion and British colonisation of South Asian countries led to an increasing preference for lighter skin and the introduction of Western notions of beauty. In India, fair skin is considered as an indicator of belonging to a higher caste, social standing and hierarchy in society, which may also lead to a preference for fair skin (Badruddoja, 2005; Chadha, 2005). Furthermore, light skin may be linked to wealth and education, whereas those with dark skin may be perceived as low-income workers (Swami et al., 2008b; Callister et al., 2011 ). 
The Social Learning theory (Bandura, 1977) proposes that learning occurs by observing others and being positively or negatively reinforced for a particular belief or behaviour. The preference for fair skin in India is largely reinforced by models and Bollywood (the Hindi-language film industry based in Mumbai, India) celebrities who advertise various products, as they are perceive to represent Indian physical appearance ideals people are expected to adhere to (Guha Ray, 2010). Such celebrities are important influences on Indian men and women as beliefs and behaviours surrounding physical appearance are conveyed indirectly through modelling, and/or directly through instruction, and verbal comments which provide reinforcement for people that these behaviours are acceptable. This type of learning also gives an individual confirmation that physical appearance (and fair skin, in particular) is a valued trait in society, and is associated with other attributes, such as attractiveness and success (McKinley, 1999; Ogden, 2010).

Women have traditionally been the focus for these products, and are indeed encouraged and expected to take various steps to achieve this ideal, with the aid of a growing market of fairness creams, skin whitening and lightening products in India and across Asia, if required. In India alone, this market is estimated at around $\$ 432$ m (Guha Ray, 2010). A popular example is the Fair \& Lovely brand that promises 'Gorepan se kahin zyada, saaf gorapan' or 'More than just fairness, clear fairness' ("Fair \& Lovely", 2011). Together, these products encourage women to conform to the light-skinned ideal. As a result, Indian women may aim to achieve the 'ivory skin model' - a term coined by Badruddoja (2005) - which aims to take into account the Indian requirement for a fair skin tone, along with the Western ideal of olive or slightly tanned skin considered attractive.

Women, regardless of culture, are more likely to perceive a greater number of, as well as more negative messages about appearance, compared to men (Gillen \& Lefkowitz, 2009). Women are aware that they will be judged on their physical appearance and related attributes, rather than how they feel or what they can do (Sahay \& Piran, 1997; McKinley, 1999). It may also be possible that Indian women are more sensitive to messages about social norms than men, and that this is perceived as a greater amount of pressure. However, it is likely that Indian men, like men living in other cultures, also perceive various pressures to conform to a certain physical ideal, as shown by past research (Adams, Turner \& Bucks, 2005). A recent growth of skin lightening products for men indicates that perhaps fair skin has also become a preference for many Indian men (Chadha, 2005; Guha Ray, 2010). Popular male celebrities endorse products such as 'Fair \& Lovely Max Fairness for Men' and 'Fair and Handsome', which promise benefits such as improved physical appearance, confidence and self-esteem (Chadha, 2005; "Fair and Handsome", 2011). These 
findings indicate that the need to conform to Indian physical appearance ideals has an important influence on the physical and psychological health of Indian men and women.

Such products are marketed in such a way that people internalise the belief that fair skin will lead to increased marriage prospects, job prospects, social status and control (Timmons, 2007; Li, Min, Belk, Kimura \& Bahl, 2008). Research looking at other ethnic groups has also shown that attractiveness leads to success; that is, more attractive individuals are more likely to experience certain advantages and successes in life than less attractive individuals (Gillen \& Lefkowitz, 2009). Thus, Indian men and women may perceive that fair skin opens doors to a variety of different areas, which dark skin may not (Chadha, 2005).

Does fair skin improve marriage prospects?

Some studies have found fair skin is idealised in Indian cultures because it may increase a person's chances of finding a suitable bride or groom, especially if the marriage is to be arranged (Pettit, 2008). This is important as marriage is considered critical for lifelong economic security within Indian cultures, even for employed women (Saran \& Eames, 1980; Dasgupta, 1998). Sahay and Piran (1997) suggested that: 'In many Indian languages, the words fair and beautiful are often used synonymously, and there is often a preference for a female with light complexion in marriage, if other considerations are equal' (p. 162). Past research has shown that even second generation South Asian women living in Western cultures, show a desire to be lighter in skin color and believe that fair skin is considered more beautiful than dark skin because it is linked to marriage prospects (Sahay \& Piran, 1997; Pettit, 2008). Indian men are also likely to state a preference for fair skin in their potential partners, regardless of their own skin tone (Jha \& Adelman, 2009).

Past research has shown that men face far less pressure than women to have fair skin (Jha \& Adelman, 2009). Darker skin tone in men may be compensated by assets such as having a well paid job, overall economic security and a good personality, whereas women are likely to be evaluated solely on their outward physical appearance (Jha \& Adelman, 2009). Thus, women with a dark or very dark skin tone may be viewed as an undesirable potential bride (Chadha, 2005; Frisby, 2006; Jha \& Adelman, 2009). As a result, Indian women may take steps to limit sun exposure to avoid tanning their skin, even if it means risking potential health benefits such as Vitamin D from sunlight (Pettit, 2008; Callister et al., 2011). 
Past research has shown that people are concerned with how they look to themselves and to others (Fallon, 1990), and any aspect of appearance can cause concern. Satisfaction with one's physical characteristics may be influenced by the social comparison process (Festinger, 1954), whereby people compare themselves to others (i.e. those similar in age, ethnicity, etc), and use them as a reference point to evaluate aspects of their own appearance such as fairness. The reality is that despite the internalisation of the fair-skinned ideal and attempts obtain this ideal by many Indian men and women, such ideals may be an unrealistic standard that many people can not achieve. Over time, internalisation of and attempts to obtain such ideas may develop into an obsession, interfering with an individual's everyday activities. This condition - known as Body Dysmorphic Disorder - may occur in individuals whose current appearance may be perceived as normal by others (see Phillips, 2009, for a review). Thus, by presenting such largely unrealistic standards of beauty and attractiveness, these ideals negatively influence individuals' body image, as physical and psychological insecurities may arise in Indian men and women when the expected results are not achieved (Badruddoja, 2005; Li et al., 2008). It is, therefore, important to investigate the patterns that are presently occurring, and the perceived reasons for any physical and psychological insecurities that arise in British Indian men and women.

The present study

It is important to investigate British Indian men and women's perceptions of Indian physical appearance ideals and related attributes as although quantitative research in South Asian cultures living in the UK is growing, there are fewer qualitative studies in comparison. Furthermore, research looking at how South Asian groups living in the UK experience exposure to various appearance ideals is understudied and needs further attention.

We can not assume, however, that all the South Asian countries and cultures are homogenous in terms of their perceptions about physical appearance (Furnham \& Adam-Saib, 2001; Wildes et al., 2007; Cummins \& Lehman, 2007). Thus, the present study will only examine the perceptions of the Indian culture, and will aim to highlight further similarities and differences within this group where possible. British Indians have had the opportunity to view and experience both the Western and Indian cultures, and are, therefore, in a unique position to provide insights into the ways in which the two cultures are similar and different, and how these cultures have evolved over time. This is useful in understanding the pressures young Indian men and women may experience in terms of physical appearance, as these may be applicable to the Indian population around the world. A detailed discussion of the 
similarities and differences between various groups are beyond the scope of this paper, but it is anticipated that these will be examined in future articles.

The aim of the present study was to investigate British Indian men and women's perceptions of Indian physical appearance ideals and related attributes. Based on the literature cited earlier, it is likely that body weight, shape and size will be an important aspect for Indian men and women, although the pressure to conform to the cultural ideals may not be as important compared to the West. It is also likely that participants will indicate a preference for fair skin in both men and women, but this attribute may be more favourable in women due to the reasons discussed earlier. As past research has shown, there is generally less pressure on men than women across different cultures to conform to ideals, and this is likely to be reiterated in the present study.

\section{Methodology}

Participants

Eight participants of Indian origin were recruited for this study, out of which four were male and four were female. Participants' age ranged from 22 to 48 years $(M=30.25$, $S D=10.29$ ), and the length of time they had lived in the UK varied from 22 to 32 years $(M=26.25, S D=4.367)$. Two of the participants ( 1 male and 1 female) had previously lived in India, whereas the other six ( 3 male and 3 female) visit the country regularly, and so would be able to provide perspectives from both the Indian and Western cultures. When asked about their marital status, six participants $(4$ male and 2 female) revealed that they were single and two were married 11 male and 1 female). Two participants were educated up to school level, two had undergraduate university degrees, whereas the remaining participants were working towards obtaining postgraduate qualifications. Further information about the participants was not provided.

As the data were analysed manually using the principles of Interpretative Phenomenological Analysis (IPA, Smith \& Osborne, 2008), a sample size of eight participants was deemed sufficient (Smith \& Osborne, 2008). This is because the aim of IPA is to explore the perceptions of a particular group in detail, which may not necessarily be statistically representative of a wider population (Yardley, 2008). (Further details about IPA are presented under the Data analysis section). All participants were recruited via a snowball sampling method, as current participants were asked to identify other appropriate individuals. The implications of recruiting participants using this method are discussed later in the paper. 
Design

In-depth semi-structured, face-to-face interviews were conducted using openended questions, in order to explore how different factors may influence pressures to conform to appearance ideals. Interviews were identified as a suitable method for the present study as they enable individuals to focalise the theoretical and conceptual factors and processes that may determine their attitudes and behaviours towards conforming to appearance ideals. Furthermore, they allow participants to provide a fuller, richer account than would be possible with quantitative methods that are often accompanied by predefined response categories. Participants are not forced to think in a particular way, and the accounts obtained have the potential to provide unexpected insights into factors, not previously considered relevant by the researchers. This is because interviews provide access to the participants' own concepts, language and natural style of discourse, which ensures rich and enlightening data. The semi-structured approach is also flexible and allows one to modify the order of the questions depending on what is relevant and important to the participant. Furthermore, participants from a variety of different backgrounds can be questioned about the same issues, but in a greater level of detail compared to questionnaires.

Materials

The interview schedule was based on a review of the relevant literature and earlier findings obtained as part of the first author's PhD thesis. However, the questions were not designed to be too specific as it was anticipated that participants would add their unique perspectives and should not feel constrained when responding. The interview schedule included questions such as 'In what ways do you think culture influences appearance in Indians?' and 'Can you think of any differences that exist between the Indian and Western cultures in terms of a man and woman's appearance?' A small pilot was carried out to ensure the questions were short and easily understandable, especially for those participants whose first language may not have been English. Any unnecessary, difficult or ambiguous questions were discarded or re-worded as appropriate. The initial interview schedule was adjusted and further questions were added to ensure in-depth conversations and flexibility of questions (i.e. the opportunity to ask additional questions depending on the responses).

Procedure

The University Ethics Committee approved this study prior to contacting participants. 
Potential participants were identified by the first author, and further participants were recruited via a snowball sampling method, as those already interviewed were asked to identify further appropriate individuals. The first author conducted all the interviews and ensured that all participants were aware of the ethical standards for conducting research with humans. All participants were asked for their written consent prior to the interviews, and were reassured of their anonymity and confidentiality as a participant. Permission to tape record the interviews was also obtained for transcription and analysis purposes.

The interviews were carried out at the university or at the participant's home. All interviews were conducted in English to ensure all participants were asked similar questions. Participants were encouraged to talk freely about the questions asked and about any other issues they felt were important. They were given opportunities to ask questions during the study, and were debriefed at the end. Interview lengths varied from 30 to 55 minutes. The transcripts were anonymised and pseudonyms were used so that the participants could not be identified by their responses.

Data analysis

IPA was used to analyse the data, where the researcher attempts to understand the experiences of participants and how the participants themselves make sense of their experiences. This qualitative research method aims to 'explore personal experience and is concerned with an individual's personal perception or account of an object or event, as opposed to an attempt to produce an objective statement of the object or event itself (Smith \& Osborne, 2008, p. 53). IPA was chosen for this study as semi-structured interviews allow participants to provide a rich account of their experiences, which means that any similarities and differences between the participants' responses can be highlighted. IPA was chosen over other qualitative research methods (such as thematic analysis) because 'IPA is a suitable approach when one is trying to find out how individuals are perceiving the particular situation they are facing, how they are making sense of their personal and social world... There is no attempt to test a predetermined hypothesis of the researcher; rather, the aim is to explore, flexibly and in detail, an area of concern.' (Smith \& Osborne, 2008, p. 55).

The two researchers (i.e. the authors of this article) individually read through all the transcripts several times to ensure familiarity with the data. The first step in the analysis was to go through a transcript and write down initial thoughts in the left hand side column and emerging theme titles or key words in the right hand side column. Then, these themes were clustered together and a coding sheet was then constructed 
containing all possible themes and sub-themes for the first interview. Some initial themes were dropped from the coding sheet at this point, if they were not rich in evidence, and/or did not fit into a main theme. References to original material were recorded under each theme, including page and line numbers, to ensure easy access to the example. Still working individually at this point, the researchers repeated this process for the remaining transcripts.

Individual interpretations were considered and evaluated in two ways. First, the researchers compared their independent readings in order to triangulate their perspectives to ensure that: 1) the analysis was not confined to one particular viewpoint, and 2) to reach an agreement for the themes and sub-themes for the sample. The discussions involved comparisons of coding themes, highlighting important examples, adding and dropping themes and sub-themes, identifying any potential instances that had not been captured and/or anticipated by either of the researchers, and highlighting any clarifications that would increase the consistency and validity of the analysis (Yardley, 2008). With continuous reference to the transcripts, connections between the individual lists of themes were made, and a master list of themes was constructed for the sample. The themes and subthemes were adjusted accordingly based on the analyses and throughout the write-up process. An additional researcher (a White British female unrelated to the study) also reviewed the data to confirm the relevancy of the themes derived by the two researchers. This additional process also promotes greater transparency in interpretations so that these were not confined to the first author's preconceptions, expectations and experiences of the Indian culture.

\section{Results and Discussion}

Four themes emerged from the data: 1) Cultural similarities and differences in physical appearance, 2) Gender differences in pressure experienced, 3) Improving physical appearance for marriage, and 4) Factors influencing appearance pressures.

Cultural similarities and differences in physical appearance

All of the participants viewed culture as a major influence on appearance ideals. They perceived various similarities and differences between the Western and Indian cultures and how these influence body image and general appearance standards. Both male and female participants highlighted important differences between the two cultures in terms of the type and level of importance they place on different aspects of appearance, as highlighted by the following quotes: 
There (India), weight isn't a problem, I don't think. There's no, there's not this need to kind of look thin or anything like that. (Female, 25 years, single)

The culture in India doesn't in itself have so much to do with appearance and body. It has more to do with poise and grace, maybe the way you dress and the way you speak. Here, I think the culture is a lot more physical, it's much more to do with the body, its appearance and its use. (Male, 44 years, married)

These quotes indicate that body representation was perceived differently in the two cultures; in India the body is viewed as more functional (i.e. What it can do), compared with the West where a greater emphasis is placed on outward physical appearance (i.e. how you look). This supports previous findings that showed different cultures place different values on appearance (Nasser, 1988, 1997). The latter quote also suggests that physical appearance is important for Indians, although the focus, and more specifically, the need to conform to the Western ideals of thinness for women and muscularity for men, may not be as strong as in the West (Wardle et al., 1993; Reddy \& Crowther, 2007). Instead, the focus is on looking and feeling healthy, rather than being a particular body weight, shape or size (Nasser, 1988, 1997). Participants explained how Indians may be more accepting of larger figures for women as they traditionally signify attributes such as affluence level and good physical health. For example:

In India, I think... its okay to be slightly chubby there, because it's a sign that you're quite affluent and you can afford to buy food and that you're healthy...you're allowed to be more bigger in India than you are here! (Female, 25 years, single)

This quote supports past research as it indicates that whereas thinness is considered desirable in women living in the West, larger figures are considered attractive in many other cultures (Nasser, 1988). For example, Nasser (1988) suggested that for an Indian Punjabi to greet you with a saying of you "look fat and fresh today" is regarded as a compliment. This can be linked to the evolutionary perspective, as larger shapes in such cultures are considered symbolic of fertility and womanhood, as well as other indicators such as longevity and affluence level. The above quote also indicates that British Indian men and women perceived that women living in India were still holding onto their traditional beliefs as they focused on looking and 
feeling physically healthy rather than conforming to the thin Western ideal for women.

This supports the findings of Warren et al. (2005) who proposed that people in nonWestern cultures may not idealise an ultrathin and unrealistic figure, but instead provide people with larger, more realistic and attainable physical ideals. They also proposed that non-Western groups may not internalise ultrathin messages because they are affiliated with a culture that does not encourage such appearance ideals (Reddy \& Crowther, 2007). Thus, although appearance is important in both cultures, the focus on appearance is different, perhaps due to the availability and accessibility of resources. Some participants believed that people in the subcontinent may not always have the resources to change their appearance as people can do in the West. A female participant suggested that people in India were better able to handle natural changes in appearance compared to the West:

I don't think people in this country especially are used to ageing...that's why they're resorting to all these anti-ageing creams and plastic surgery...you know, one white hair and we freak out, but in India you know, I think its okay... they're more accepting. (Female, 25 years, single)

This quote shows some cultural differences exist in the extent to which people are able to, and feel the need to change their appearance in the two cultures. This may be because perhaps Indians experience different pressures to conform to certain ideals, compared to those in the West (Timmons, 2007). These results are consistent with past research that also found Indian men and women may be better at dealing with natural changes that occur with age (Bush et al., 2001). Furthermore, these differences may exist because the Western world has more options to change one's appearance if needed (i.e. with the use of cosmetic surgery). Indians on limited incomes and those living in rural areas with little or no Western influence may view change in appearance as something natural that can not and should not be altered (Crisp, 2002).

Gender differences in pressure experienced

All the participants felt that both men and women experience some pressure to conform to desirable cultural standards of appearance. They stated that the sources and levels of concern may vary depending on factors such as identification with a particular culture and parental influence in Indians (Hill \& Bhatti, 1995; Dasgupta, 1998). These results are consistent with past studies that also found a similar pattern of results in different ethnic groups (Cash \& Pruzinsky, 2004; Jones, Vigfusdottir \& Lee, 
2004). The following quote was in response to a question asking about the level of appearance-related pressure experienced by men and women:

I think they're about the same, I mean you know, it's... different ways, but the amount of pressure is about the same. (Male, 22 years, single)

It was interesting that throughout conversations about appearance-related pressures, participants naturally focused on the pressures that concern women in both cultures. The male participants frequently discussed the pressures on women, despite being aware of the pressures that exist for men as well. All eight participants, acknowledged that women were more likely to experience pressure to conform to societal and cultural ideals, compared to men (Strahan et al., 2006):

I think they have more pressure to look prettier, whereas guys can just be, its not as expected, they're not as expected to be as groomed as girls are. (Female, 26 years, single)

It may also be that women are generally more sensitive to messages about social norms than men, and that this is perceived as a greater amount of pressure, as in the present study (Gillen \& Lefkowitz, 2009). Other studies have found that men are becoming increasingly aware of the cultural norms and ideals they are expected to conform to (Adams et al., 2005). The participants generally felt that it was only recently that men (of all cultures) were feeling the pressure to conform to an ideal, although they have always been aware of these ideals:

I mean for guys you know...it's only in recent times maybe, where the whole physique thing has become more important... there's a whole new awareness of grooming, and grooming products...I think the pressures on women are slightly different, the looking good has always been there. (Male, 44 years, married)

These findings indicate that although Indian men and women face pressure to conform to the ideals, women are exposed to a much more consistent and persuasive message about how they need to look to be accepted in society, compared to men (Strahan et al., 2006). Over half of the participants in the present sample suggested that the pressure men and women face may be age-related, and so the expectations to look physically attractive may change as one gets older (Tiggemann, 2004). They suggested that the pressure may decrease over time because people have less perceived and actual control over their physical appearance (Grogan \& Richards, 2002): 
I think in their mid 20s, boys start to realise that you know ageing is something that will happen! You know, they can't avoid it and I think they'll try anything, to live their younger years again...I think the age thing becomes this thing that they can't control. (Female, 25 years, single)

The above quote indicates that some men may find it difficult to handle natural changes in their appearance, as perceived by women. This notion was echoed by a male participant, who explained how age-related changes had affected his thoughts and expectations about his ideal appearance, as illustrated by the following quote:

In my teens and twenties, I wanted to be perfect. But now that I'm in my mid-thirties, you begin to sort of care less about these things. And certainly when you're in your forties and then fifties, the older you grow, the less you care about these things and you think okay, don't worry about it. (Male, 32 years, single)

These quotes indicate that men are concerned with their appearance, but this concern is not always made explicit, as it is not expected from them (Grogan \& Richards, 2002; Ricciardelli, McCabe \& Ridge, 2006). Similar to women, men also have a personal view of themselves (i.e. how they see themselves), as well as a social view of the self (i.e. how they think others see them), which may lead to appearance concerns if there is a discrepancy between these two views. Interestingly, there were many instances during the discussions where the interaction between gender and ethnicity was not considered, but were perceived as two separate entities. This indicated that participants perceived that there were some pressures that all men and women face regardless of cultural affiliation, whereas there are others that are more prevalent in some cultures.

Improving physical appearance for marriage

An important and reoccurring theme that cropped up during the interviews was the issue of conforming to certain physical appearance ideals in order to find a suitable partner for marriage. The notion of what is meant by 'beauty' was discussed to a great extent by some of the participants. They gave various definitions of what they thought beauty was, based on their personal experiences and their perceptions of how the Indian culture defines it. Participants' definitions of beauty and physical appearance were generally similar to those cited by Timmons (2007): "The definition of beauty in the Western world is linked to anti-aging... In Asia, it's all about being two 
shades lighter." Female participants commonly associated beauty with skin colour; they perceived that a fair woman would be considered more beautiful than a woman with a darker skin tone (Sahay \& Piran, 1997; Badruddoja, 2005; Jha \& Adelman, 2009):

There's so much emphasis on looks in India, especially about being fair. If you're dark, then...you're put in the ugly group automatically...they don't go out in the sunlight during the day, they always go out at night and you know...especially if they're not married, they really have to, they look after themselves you know. (Female, 25 years, single)

The notion of having fair skin was linked to implications for finding a suitable partner for marriage, particularly if the marriage was to be arranged through social contacts (Pettit, 2008). It was implied that women with fairer skin tones would have better chances of getting married and seen as more desirable than those with darker tones, as illustrated by the following quote:

I think a fair girl would have better marriage prospects than a dark one... when my mum was going through marriage proposals... they'd send my aunt away in case the guys prefer her...she's taller, slimmer and fairer. (Female, 25 years, single)

Thus, participants' thoughts and expectations of how a woman should look may be influenced by the experiences of those around them. That is, if a woman is tall, slim and fair, then her chances of finding a suitable match are perceived to increase, as she is considered more desirable than a woman with darker skin (Fallon, 1990; Sahay \& Piran, 1997). As discussed in the introduction of this article, Sahay and Piran (1997) suggested that: 'In many Indian languages, the words fair and beautiful are often used synonymously, and there is often a preference for a female with light complexion in marriage, if other considerations are equal' (p. 162). Around half of the participants in the present study were in agreement with this idea as they believed that light skin is perceived as more attractive than dark skin in the Indian cultures, as well as other Asian cultures (Li et al., 2008). These findings are also almost identical to the responses of South Asian women living in New Zealand, as found by Pettit (2008):

"If you're fair it's really...a plus point, particularly in arranged marriages where looks is what they focus on [in] the girl... I could guarantee if you talk to young second generation immigrants from the sub-continent, like females, they would mention the pressure of being fair" (Pettit, 2008, p. 146) 
As fair skin was perceived to increase one's likelihood of an arranged marriage, this suggests that some aspects of physical appearance are more important than others in Indian cultures. Both male and female participants felt that the aim for Indian women was to look more physically attractive, which predominately includes having fair skin, followed by an acceptable body weight, shape and size. As the participants suggested in the first theme, it may be that many Indian women do not focus on body weight, shape and size as much as skin tone, because they do not need to; they may be naturally conforming to the Western ideals for women. Therefore, they may focus on improving other aspects of their physical appearance, such as attempting to make their skin lighter. This preference may be a result of advertising by Indian celebrities, who provide reinforcement for people that fair skin is a valued trait in society, and is associated with other attributes, such as attractiveness and success (McKinley, 1999; Chadha, 2005; Guha Ray, 2010; Ogden, 2010):

I think for women in India, there's definitely this whole factor of looking like the stars. Outside the metropolitan cites, I just don't think this is an issue. But, where there's a lot of advertising, where there's access to the media, there's a very strong move right now over there for youngsters to look like their role models. (Male, 44 years, married)

Indeed, a fast growing market of skin whitening and lightening products in India encourage women to use these products, leading to physical and psychological insecurities in unmarried Indian women (Badruddoja, 2005; Li et al., 2008). Interestingly, the men in the present study did not talk at lengths about similar products that are available to Indian men. It may be that these participants did not feel the need to conform to the expectations like Indian women do, because darker skin colour in men can be compensated by other features not related to physical appearance (Jha \& Adelman, 2009).

Factors influencing appearance pressures

Although a lot of pressure to conform to the Indian physical appearance ideals was perceived to come directly from wider cultural beliefs about how men and women should look, some participants felt that the pressure experienced was also influenced by other factors. The female participants, in particular, acknowledged that in South Asian cultures, daughters are more likely to experience appearance pressure from their parents than sons (Badruddoja, 2005): 
It's this pre-conceived conception of that's how you're meant to be...they expect you to be tall and slim and fair. (Female, 26 years, single)

As illustrated in the above quotation, participants believed that parents may be encouraging their daughters to conform to Indian cultural appearance ideals of being fair skinned, and the Western ideal of slimness. The focus on daughters may be because beauty is considered more important when defining women than men. When a man is dark skinned, this can be compensated by other attributes such as having a well paid job and a good personality, whereas women may be defined solely by their outward physical appearance (Badruddoja, 2005; Pettit, 2008). For instance:

There's so much pressure on girls full stop...the guy can be like whatever. (Female, 26 years, single)

Notably, it was often mothers who were perceived as influencing their daughter's appearance more than their fathers (Thelen \& Cormier, 1995; McCabe \& Ricciardelli, 2001), as illustrated by the following quote:

I don't think dads' have much of an influence, I think it's more of the female side of the family. Asian mum's have a thing about you know being slim. (Female, 26 years, single)

One explanation for this pattern may be that daughters generally spend more time with their mothers than with their fathers, and so they may learn about cultural conventions through verbal instruction or comments and/or social learning. Past studies conducted with adolescent girls have shown that parents can be an important source of information about societal and cultural body ideals (Nowak, 1998; Crisp, 2002; Gillen \& Lefkowitz, 2009). In this case, mothers may teach their daughters about how they need to look in order to find a suitable partner for marriage within their community. Participants in the present study also felt that mothers expected their daughters to conform to their societal physical ideals, so that their chances of finding an appropriate partner would increase (Jayakar, 1994; Mumford \& Choudry, 2000; Mujtaba \& Furnham, 2001). This expectation might add pressure on a daughter to conform to the Indian ideals of physical attractiveness, as encouraged by their mothers. Nevertheless, one female participant also noted that despite this pressure, mothers can also provide positive feedback and encouragement, as illustrated by the following quote: 
If I say 'Oh my God I've put on weight', mum says 'You haven't, you look fine, you look beautiful as you are'. (Female, 25 years, single)

There was a debate amongst the participants whether this pressure for women would remain after marriage. The male participants felt that this pressure would decrease considerably after marriage as the goal of finding a suitable partner would be achieved, as illustrated by the following quotes:

Marriage is the only hurdle...prior to marriage, girls go out of their way to look really good... after marriage, both parties can ease down, because they're married, they've achieved what they set out to do. (Male, 32 years, single)

I think that definitely happens in Asians everywhere; they tend to forget about their appearance after they're married. (Male, 23 years, single)

These quotations indicate that the need to conform to appearance ideals for women is only prevalent pre-marriage, and that marriage is a goal Indian men and women aspire towards. As perceived by the male participants in the present study, women may not experience the same level of appearance-related pressure after marriage, as they have now found their spouse, with whom they are expected to be for the rest of their life (Saran \& Eames, 1980; Dasgupta, 1998). This easing of pressure may also be linked to other aspects of life, including career development and children, which perhaps affect women more than men post-marriage (Grogan, 1999; Tiggemann, 2004). More important priorities may take preference over conforming to the societal ideals of physical appearance after marriage. For instance, one male participant said:

Once you get to a certain age, it doesn't really matter what you look like...you can see a lot of couples that lose their looks after they get married...it's harder to look the same once you're married because there are other pressures. (Male, 22 years, single)

Two other male participants felt that it was unfair that Indian women no longer have to conform to the ideals after marriage, whereas the expectation remains for men:

I think that's highly unfair as men tend to stay in shape, but women tend to get out of shape. (Male, 23 years, single) 
The four female participants contradicted this argument as they suggested that women were still expected to conform to certain ideals as they get older, despite going through various experiences (i.e. pregnancy and childbirth) that have a significant impact on their physical appearance. They believed that these ideals change with age, but gender differences in the pressure experienced to look physically attractive still existed even after marriage:

When they get married, there's this whole emphasis that the woman has to be like this flower, delicate, elegant and beautiful and, so I think there's more pressure on them to look nice all the time. It doesn't matter if the husband you know puts on 10 stones...but the woman, she has to look presentable in the public eye. (Female, 25 years, single)

This quote suggests that even after marriage, women are expected to conform to societal standards of appearance, whereas men may not face such pressures to the same extent (Badruddoja, 2005). These findings support past research as Strahan et al. (2006) found that both sexes felt that women were more likely to experience pressure to conform to societal and cultural ideals, compared to men, perhaps because women realise that they likely to be evaluated on their outward physical appearance. Women, in particular, may also have more realistic expectations about how they can look as they age (Grogan, 1999). Studies conducted with African American, Latino American and European American participants support these findings (Gillen \& Lefkowitz, 2009), indicating that there is generally less pressure on men than women across different cultures to conform to physical ideals. Together, these findings indicate that gender can potentially influence appearancerelated pressures experienced to conform to the ideals.

\section{General discussion}

Conclusions and implications

The aim of the present study was to investigate British Indian men and women's perceptions of Indian physical appearance ideals and related attributes. It was anticipated that Indian men and women would consider body weight, shape and size as important aspects of appearance, but the pressure to conform to the cultural ideals would not be as powerful compared to the West. It was also likely that both male and female participants would prefer fair skin, and that there would be generally less pressure on men than women to conform to such ideals as shown by past research. 
The analysis indicated that British Indian men and women living in the UK were aware of the Indian physical appearance ideals that exist for men and women, and that they were perceived to be applicable to the Indian population living outside of India as well. The focus of conversations suggested that people living in India were perceived to be holding onto their traditional beliefs as they focused on looking and feeling physically healthy more than conforming to the appearance ideals (although slimness in women was still considered important). An exception to these perceptions was that all of the female participants spoke about how beauty is associated with skin colour. They perceived that Indian women, in particular, are expected to have (or make attempts to have) fair skin, so that their chances of finding a suitable partner for marriage would increase, especially if their marriage is likely to be arranged (Jayakar, 1994; Mumford \& Choudry, 2000).

Interestingly, the majority of the responses focused on the pressures faced by Indian women, and only a small percentage concentrated on Indian men. Despite acknowledging that Indian men also face some pressures to conform to the cultural ideals, the general consensus amongst participants was that regardless of culture, women are more likely to perceive more negative messages about appearance, compared to men (Gillen \& Lefkowitz, 2009). The participants believed that the cultural ideal for men is more flexible, and that the ideal man may fit into a variety of other categories and still be viewed as attractive (Strahan et al., 2006). These messages were perceived to be reinforced and promoted mainly by mothers and the media, through processes such as social learning, social comparison and internalisation (Strahan et al., 2006), and linked with finding a suitable partner for marriage (Badruddoja, 2005; Jha \& Adelman, 2009).

These findings have various physical, psychological and social implications for Indian men and women. Many people are aware that skin lightening and whitening creams often contain bleaching and/or burning agents, which can lead to physical skin damage, yet they continue to use these products in their attempts to conform to a lighter skin tone ideal (Timmons, 2007). Furthermore, in taking steps to limit sun exposure to avoid tanning their skin, Indian men and women may be risking potential health benefits such as Vitamin $D$ and other nutrients from natural sunlight (Pettit, 2008; see Callister et al., 2011, for an overview of the health implications of not obtaining sufficient natural levels of sunlight).

Failure to achieve such ideals over time may also have a significant impact on an individual's self-esteem and confidence levels, as well as encouraging the development of conditions such as Body Dysmorphic Disorder (Phillips, 2009), which 
may be exaggerated by processes such as social comparison and feedback from others. If one product does not show immediate results as advertised, then an individual may move onto trying a different product due to the choice of products available all promising better results than others. This may result in a cycle of experimentation, and possibly, frustration when the fair ideal is still not achieved. All this is likely to have a significant impact on an individual's skin condition, their overall self-worth, as well as their financial circumstances.

Such ideals may be unrealistic for many women regardless of cultural affiliation, as summed up by Sahay and Piran (1997) in this statement: 'The tall, thin, white-skinned, blue-eyed, blonde Western ideal of the beauty myth is unattainable for most women of any race or ethnic background' (p. 169). Despite being aware of these issues, people may continue to take steps to achieve an impossible standard that do not reflect the average population of that culture. This may be due to the perception that such ideals are linked to a variety of other attributes, including: improved job prospects, social status, success and control (Timmons, 2007; Li et al., 2008; Gillen \& Lefkowitz, 2009), which will continue to be important areas for people in all cultures. These perceptions, in turn, will have wider social implications for British Indian adults' of which ideals they should aim to achieve. The perception of Indian females having to conform to both the Indian ideal of fair skin and the Western ideal of slimness may lead to greater feelings of anxiety, and, in turn, negative body image, especially when one or both of these ideals are not achieved. Increasing awareness of this beauty myth may help to reduce the appearance-related pressure to conform to societal and cultural expectations, for women regardless of cultural affiliation.

Strengths and limitations

It is important to consider the strengths and shortcomings of the present study, as these will have implications for future research in this area. The present research investigated two relatively understudied groups, British Indian men and women for their perceptions of Indian physical appearance ideals and related attributes. An important aspect of the present study is that it considered the perceptions of both Indian men and women, which is important because men are often overlooked in research involving physical appearance as they are often difficult to recruit. Examining the perceptions of people belonging to non-Western cultures of origin will add to our understanding of how cultural values and ideals influence aspects of, and body image as a whole.

An advantage of using semi-structured interviews was that participants were able to freely discuss topics that were meaningful and culturally significant to them. For 
example, although the preliminary interview schedule did not contain any references to marriage-related pressure, this topic naturally arose in the conversations. Participants also spoke about their personal experiences from both Western and Indian perspectives which led to rich, insightful and natural data. The flexibility of the approach allowed the researcher to follow the route the participants deemed as important to them. Thus, gathering qualitative data using semi-structured interviews is beneficial for the investigation of appearance ideals in different cultures.

We must be aware of the fact that although the Indian culture was discussed as a complete entity in the present study, regional differences in appearance ideals are likely to exist. For instance, fair skin may be more valued in some regions within India than others, particularly where resources to obtain fairer skin are available and accessible. This preference will have implications for the perceived pressure to conform to such ideals, and the level of influence from related sources. Noticeably, the ancestors of the participants in the present study originated from Northern (i.e. Punjab) and Western (i.e. Gujarat) regions of India, where on average, skin tends to be lighter compared to other regions such as in the South (Badruddoja, 2005). Thus, a preference for fair skin may be a common norm within these participants' societies, hence the conformity in responses. However, this is not to say that one region will experience more or less pressure than another on a particular attribute; skin tone is purely one example, and it is likely that there are many more bodyrelated ideals a native of a region is expected to adhere to. Future studies should ask participants to define specific regional appearance ideals that they are familiar with, which will help to further contextualise the responses obtained here.

There are also other areas worthy of discussion. Firstly, we must consider that recruiting participants using a snowball sample may have restricted the range of perspectives discussed in the interviews. Friends and families often share similar attitudes and beliefs this may have influenced the level of similarity in their responses to the questions. Future studies on similar topics should aim to recruit participants using a variety of more randomised methods, so that a wider range of perceptions can be obtained and a larger picture of the patterns occurring within British Indians living in the UK can be developed. Nevertheless, most of the responses obtained in the present study were consistent with past research in this area, indicating that the most important areas related to Indian physical appearance ideals were covered in the interviews. Furthermore, participants provided insights from both the Western and Asian cultures, as two of the participants had previously lived in India, whereas six visit the country regularly. As the participants had experienced both cultures, they were able to provide richer, detailed accounts, and how the processes were similar and different in the two cultures. 
Secondly, we must be aware of the terms and concepts used by the participants in the present study. For example, the terms 'West' and 'Western' were used to describe the British culture, although geographically, these terms can have various connotations. Thus, future studies could ask participants to specify the meanings of these terms when used by themselves and/or the interviewer. The third point to consider is that additional demographic information about the participants would have enabled the authors to explore the responses of the participants even further. For example, aspects such as acculturation levels, ethnic identity, reason for immigration (where relevant), as well as others are important factors that may have the potential to influence the extent to which an individual feels he/she should attempt to conform to the appearance ideals (Ball \& Kenardy, 2002; Farver et al., 2002). It is anticipated that detailed supplementary information about participants will be obtained in future studies.

And lastly, we must also remember that the responses obtained in the present study are simply perceptions of British Indians of what features the Indian appearance ideals may include. At least three of the participants had not visited India recently, and so may have obtained information about the culture through various forms of media and/or social contacts. Considering India's rapid social, cultural and economic growth, an investigation into the extent to which participants' perceptions were representative of actual customs in India itself was beyond the scope of the present study. Further investigation into this area may involve conducting similar interviews with those residing in India to investigate the extent of similarity in perceptions and responses. Detailed investigations of the interactions between various intrapersonal and interpersonal variables may also determine how cultural ideals of physical appearance develop over time.

\section{Overall conclusions}

Notwithstanding these issues, this qualitative study has provided an important insight into the appearance-related pressures faced by young Indians today as perceived by British Indian men and women. Factors such as gender, maternal encouragement and the media were perceived as important influences on the pressure experienced to conform to the cultural ideals of Indian physical appearance, which seem to be perceived as somewhat different to the Western ideals of thinness for women and muscularity for men. Internalisation of these ideals has implications for the physical and psychological health of Indian women, and to a lesser extent Indian men, as discussed in this article. Future research should aim to build upon the findings of the present study by addressing the limitations as discussed earlier. Through both 
qualitative and quantitative studies, we will be able to learn more about how different South Asian groups living in the UK experience exposure to various appearance ideals.

\section{Acknowledgements}

We would like to thank the participants who gave up their time to contribute to this study. We are also very grateful to Dr Debbie Smith for her kind help with the data analysis.

\section{References}

Adams, G., Turner, H., \& Bucks, R. (2005). The experience of body dissatisfaction in men. Body Image, 2, 271-283.

Badruddoja, R. (2005). Color, Beauty, and Marriage: The Ivory Skin Model. South Asian Graduate Research Journal, 15, 43-79.

Ball, K., \& Kenardy, J. (2002). Body weight, body image and eating behaviours: Relationships with ethnicity and acculturation in a community sample of young Australian women. Eating Behaviors, 3 (3), 205-216.

Bandura, A. (1977). Social Learning Theory. New York: General Learning Press.

Bush, H.M., Williams, R.G.A., Lean, M.E., \& Anderson, A.S. (2001). Body image and weight consciousness among South Asian, Italian and general population women in Britain. Appetite, 37, 207-215.

Callister, P., Galtry, J., \& Didham, R. (2011). The risks and benefits of sun exposure: should skin colour or ethnicity be the main variable for communicating health promotion messages in New Zealand? Ethnicity and Health, 16 (1), 57-71.

Cash, T.F., \& Henry, P.E. (1995). Women's body image: The results of a national survey in the U.S.A. Sex Roles: A Journal of Research, 33 (1-2), 19-28.

Cash, T.F., \& Pruzinsky, T. (2004). Body Image: A Handbook of Theory, Research, and Clinical Practice (Eds.). The Guildford Press. New York. 
Chadha, M. (2005). Indian men go tall, fair and handsome. Retrieved May 26, 201 1, from http://news.bbc.co.uk/1/hi/world/south_asia/4396122.stm.

Cheney, A.M. (2010). 'Most Girls Want to be Skinny': Body (Dis)Satisfaction Among Ethnically Diverse Women. Qualitative Health Research, published online 9 December 2010, doi: $10.1177 / 1049732310392592$.

Crisp, A.H. (2002). A tale of corruption. British Journal of Psychiatry, 180, 480-482.

Cummins, L.H., \& Lehman, J. (2007). Eating disorders and body image concerns in Asian American women: Assessment and treatment from a multicultural and feminist perspective. Eating Disorders, 15 (3), 217-230.

Dasgupta, S.D. (1998). Gender roles and cultural continuity in the Asian Indian immigrant community in the U.S. Sex Roles: A Journal of Research, 38, 953-974.

Fair and Handsome (2010). Retrieved May 26, 2011, from

http://www.fairandhandsome.net/.

Fair \& Lovely (2011). Retrieved May 26, 2011, from

http://www.fairandlovely.in/default.aspx.

Fallon, A.E. (1990). Culture in the mirror: Sociocultural determinants of body image. In T.F. Cash \& T. Pruzinsky (Eds.), Body Images: development, deviance and change (pp. 80109). New York: Guildford.

Farver, J.A.M., Bhadha, B.R., \& Narang, S.K. (2002). Acculturation and psychological functioning in Asian Indian adolescents. Social Development, 11 (1), 11-29.

Festinger, L. (1954). A theory of social comparison processes. Human Relations, 7, 117140.

Frisby, C.M. (2006). "Shades of beauty": examining the relationship of skin color to perceptions of physical attractiveness. Facial Plastic Surgery, 22 (3), 175-179.

Furnham, A., \& Adam-Saib, S. (2001). Abnormal eating attitudes and behaviours and perceived parental control: A study of White British and British-Asian school girls. Social Psychiatry and Psychiatric Epidemiology, 36 (9), 462-470.

Gillen, M.M., \& Lefkowitz, E.S. (2009). Emerging adults' perceptions of messages about physical appearance. Body Image, 6, 178-185. 
Grabe, S., \& Hyde, J.S. (2006). Ethnicity and body dissatisfaction among women in the United States: A meta-analysis. Psychological Bulletin, 132 (4), 622- 640.

Grogan, S. (1999). Body Image: Understanding Body dissatisfaction in men, women and children. Routledge.

Grogan, S. (2006). Body image and health: Contemporary perspectives. Journal of Heath Psychology, 11 (4), 523-530.

Grogan, S., \& Richards, H. (2002). Body image: Focus groups with boys and men. Men and Masculinity, 4, 219-232.

Guha Ray, S. (2010). India's unbearable lightness of being. Retrieved May 26, 201 1, from http://news.bbc.co.uk/1/hi/world/south_asia/8546183.stm.

Hill, A.J., \& Bhatti, R. (1995). Body shape perception and dieting in preadolescent British Asian girls: links with eating disorders. International Journal of Eating Disorders, 17, 175-83.

Jayakar, K. (1994). Women of the Indian subcontinent. In L. Comas-Diaz and B. Greene (Eds.). Women of color: Integrating ethnic and gender identities in psychotherapy (pp. 161-181). New York: Guilford Press.

Jha, S. \& Adelman, M. (2009). Looking for Love in All the White Places: A Study of Skin Color Preferences on Indian Matrimonial and Mate-Seeking Websites. Studies in South Asian Film and Media, 1, 65-83.

Jones, D.C., Vigfusdottir, T.H., \& Lee, Y. (2004). Body image and the appearance culture among adolescent girls and boys: An examination of friend conversations, peer criticism, appearance magazines, and the internalization of appearance ideals. Journal of Adolescent Research, 19, 323-339.

Kennedy, M.A., Templeton, L., Gandhi, A., \& Gorzalka, B.B. (2004). Asian body image satisfaction: Ethnic and gender differences across Chinese, Indo-Asian, and Europeandescent students. Eating Disorders, 12 (4), 321-336.

Li, E.P.H., Min, H.J., Belk, R.W., Kimura, J., \& Bahl, S. (2008). Skin Lightening and Beauty in Four Asian Cultures. Advances in Consumer Research, 35, 444-449.

Malhotra, S., \& Rogers, E.M. (2000). Satellite television and the new Indian woman. International Communication Gazette, 62, 407-429. 
McCabe, M.P., \& Ricciardelli, L.A. (2001). Parent, peer, and media influences on body image and strategies to both increase and decrease body size among adolescent boys and girls. Adolescence, 36, 225-240.

McKinley, N.M. (1999). Women and objectified body consciousness: Mothers' and daughters' body experience in cultural, development, and familial context. Developmental Psychology, 35, 760-769.

Mumford, D.B., \& Choudry, I.Y. (2000). Body dissatisfaction and eating attitudes in slimming and fitness gyms in London and Lahore: A cross-cultural study. European Eating Disorders Review, 8, 217-224.

Mujtaba, T., \& Furnham, A. (2001). A cross-cultural study of parental conflict and eating disorders in a non-clinical sample. International Journal of Social Psychiatry, 47, 24-35.

Nasser, M. (1988). Culture and weight consciousness. Journal of Psychosomatic Research, 32, 573-577.

Nasser, M. (1997). Culture and weight consciousness. Routledge: London.

Nowak, M. (1998). The weight-conscious adolescent: Body image, food intake, and weight-related behaviour. Journal of Adolescent Health, 23, 389-398.

Ogden, J. (2010). The psychology of eating: from healthy to disordered behaviour (2nd ed.). Wiley-Blackwell.

Paquette, M.C., \& Raine, K. (2004). Sociocultural context of women's body image. Social Science and Medicine, 59 (5), 1047-1058.

Pettit, F. (2008). Factors influencing sun exposure behaviours of South Asian women aged 18-40 living in Auckland. In S. Tse, A. Sobrun-Maharaj, S. Garg, M.E. Hoque \& Y. Ratnasabapathy (Eds.), Building healthy communities. Proceedings of the Third International Asian Health and Wellbeing Conference, September 8-9 (pp. 139-150). Auckland, New Zealand: University of Auckland.

Phillips, K.A. (2009). Understanding Body Dysmorphic Disorder. Open University Press, USA.

Reddy, S.D., \& Crowther, J.H. (2007). Teasing, Acculturation, and Cultural Conflict: Psychosocial correlates of body image and eating attitudes among South Asian women. Cultural Diversity and Ethnic Minority Psychology, 13, 45-53. 
Ricciardelli, L.A., McCabe, M.P., \& Ridge, D. (2006). The construction of the adolescent male body through sport. Journal of Health Psychology, 11, 577-587.

Sahay, S., \& Piran, N. (1997). Skin-Color Preferences and Body Satisfaction Among South Asian-Canadian and European-Canadian Female University Students. Journal of Social Psychology, 137, 161-171.

Saran, P., \& Eames, E. (1980). The New Ethnics. Asian Indians in the United States (Eds.). Praeger Publishers.

Smith, J.A., \& Osborn, M. (2008). Interpretative phenomenological analysis. In J.A. Smith (Ed.), Qualitative Psychology: A Practical Guide to Methods (2nd ed., pp. 53-80). London: Sage.

Strahan, E.J., Wilson, A.E., Cressman, K.E., \& Buote, V.M. (2006). Comparing to perfections: How cultural norms for appearance affect social comparisons and selfimage. Body Image, 3, 211-227.

Stice, E. (1994). Review of the evidence for a sociocultural model of bulimia nervosa and an exploration of the mechanisms of action. Clinical Psychology Review, 14 (7), 633-661.

Swami, V., Furnham, A. \& Joshi, K. (2008a). The influence of skin tone, hair length, and hair colour on ratings of women's physical attractiveness, health and fertility. Scandinavian Journal of Psychology, 49 (5), 429-437.

Swami, V., Rozmus-Wrzesinska, M., Voracek, M., Haubner, T., Danel, D., Pawlowski, B...\& Furnham, A. (2008b). The influence of skin tone, body weight, and hair colour on perceptions of women's attractiveness and health: A cross-cultural investigation. Journal of Evolutionary Psychology, 6 (4), 321-341.

Thelen, M.H., \& Cormier, J.F. (1995). Desire to be thinner and weight control among children and their parents. Behavior Therapy, 26, 85-99.

Tiggemann, M. (2004). Body image across the adult life span: stability and change. Body Image, 1, 29-41.

Timmons, H. (2007). Telling India's modern women they have power, even over their skin tone. Retrieved May 26, 2011 , from

http://www.nytimes.com/2007/05/30/business/media/30adco.html. 
Wardle, J., Bindra, R., Fairclough, B., \& Westcombe, A. (1993). Culture and body image: body perception and weight concern in young Asian and Caucasian British women. Journal of Community and Applied Social Psychology, 3, 173-181.

Warren, C.S., Gleaves, D.H., Cepeda-Benito, A., del Carmen Fernandez, M., \& RodriguezRuiz, S. (2005). Ethnicity as a protective factor against internalization of a thin ideal and body dissatisfaction. International Journal of Eating Disorders, 37, 241-249.

Wildes, J.E., Emery, R.E., \& Simons, A.D. (2001). The roles of ethnicity and culture in the development of eating disturbance and body dissatisfaction: A meta-analytic review. Clinical Psychology Review, 21 (4), 521-551.

Wiseman, C.V., Gray, J.J., Mosimann, J.E., \& Ahrens, A.H. (1992). Cultural expectations of thinness in women: An update. International Journal of Eating Disorders, 11 (1), 85-89.

Wood-Barcalow, N.L., Tylka, T.L., \& Augustus-Horvath, C.L. (2010). "'But I Like My Body"': Positive body image characteristics and a holistic model for young-adult women. Body Image, $7,106-116$.

Yardley, L. (2008). Demonstrating validity in Qualitative Psychology. In J.A. Smith (Ed.), Qualitative Psychology: A Practical Guide to Methods (2nd ed., pp. 235-251). London: Sage.

About the authors:

Dr. Savita Bakhshi previously worked as a Research Fellow at the School of Psychology, London Metropolitan University. Her primary research interests include the relationships between body image, food, health, exercise and the media in different ethnic groups.

Dr. Anna Baker is a Principal Lecturer in Health Psychology, and course leader MSc Health Psychology at the School of Psychology, London Metropolitan University. Her primary research interests include: obesity treatment and management, cancer risk in ethnic minorities, diabetes, psychosocial predictors of dietary behaviour, and developing behaviour change interventions.

Address for correspondence: Dr Anna Baker, School of Psychology, Faculty of Life Sciences, London Metropolitan University, Calcutta House, Old Castle Street, London E1 7NT, UK.

Email: a.baker@londonmet.ac.uk 